\title{
The Multiple Dimensions of Expanded Access to Health Information: Don Lindberg and the U.S. National Library of Medicine
}

\author{
Betsy L. HUMPHREYS ${ }^{\mathrm{a}, 1}$ \\ ${ }^{a}$ U.S. National Library of Medicine (retired)
}

\begin{abstract}
When Donald A. B. Lindberg M.D. became Director of the U.S. National Library of Medicine in 1984, trained searchers, primarily librarians, conducted less than three million searches of NLM databases. They paid for their fair share of the commercial telecommunications costs to reach NLM's computer system. In 2015 when Lindberg retired, millions of scientists, health professionals, patients, members of the public, and librarians conducted billions of free searches of NLM's greatly expanded electronic resources via the Internet. Lindberg came to NLM intending to expand access to biomedical and health information along multiple dimensions: reaching more users, providing more types and volumes of information and data; and improving the conceptual, technical, and organizational connections needed to provide information to users when and where it is needed. By any measure he and NLM were spectacularly successful. This chapter discusses some key decisions and developments that contributed to that success.
\end{abstract}

Keywords. Donald A.B. Lindberg M.D., U.S. National Library of Medicine, MEDLINE, Internet Access, Consumer Health Information, History, Librarians

\section{Introduction}

Donald A.B. Lindberg M.D. became Director of the U.S National Library of Medicine (NLM) in August 1984. In that fiscal year, trained searchers, primarily librarians, at 2,461 U.S. institutions conducted 2.8 million searches of bibliographic, thesaurus, chemical, toxicological, and cancer information databases on NLM's computer system, an 11 percent increase from the previous year. All indexing and cataloging data available online at NLM were keyed de novo for the Library's databases. Some of the data in the factual databases were received on magnetic tape from other federal agencies and organizations. Online users paid fees to cover their proportional share of the cost of the commercial value-added telecommunications networks used to reach NLM's computer system. NLM licensed MEDLINE, its premier database of indexed citations and abstracts, to other U.S. online database providers and had formal agreements with the Pan American Health Organization and the governments of 13 countries to facilitate access outside the U.S. Some international partners received copies of the databases on magnetic tape and mounted them locally using their own software or copies of NLM's ELHILL retrieval software; others managed online access to NLM's system in Bethesda

\footnotetext{
${ }^{1}$ Corresponding Author, Betsy Humphreys. E-mail: betsyhumphreys@verizon.net
} 
MD for users in their countries. By 1984 standards, NLM's databases were widely accessible and very heavily used.

By the time Lindberg retired in March 2015, millions of scientists, health professionals, patients, members of the public, and librarians worldwide conducted billions of free searches of NLM electronic resources via the Internet each year. The amount of information and data NLM organized and disseminated electronically was enormous, including richly linked bibliographic, molecular biology, genetic, genomic, biochemical, chemical, toxicological, environmental, and clinical trials data; born-digital and digitized full text; still, moving, and high resolution born-digital images; scientific and health data standards; informatics tools for system developers; and health information for the public. Thousands of individuals and organizations submitted data for inclusion in NLM's electronic resources. Users searched or downloaded information directly from an NLM Web site, found it via an Internet search engine, or used an "app" that provided value-added access to NLM data. Thousands of commercial and non-profit system developers and scientists regularly used NLM applications programming interfaces (APIs) or download sites to obtain data for their systems, products, and research.

Important prerequisites for this massive expansion in access to biomedical information were in place when Lindberg arrived at NLM. They included a mission broad enough to encompass great expansion, i.e.,"...to assist the advancement of medical and related sciences and to aid the dissemination and exchange of scientific and other information important to the progress of medicine and to the public health;" a multidisciplinary staff with a wide range of relevant expertise and experience; existing highly regarded information services on which to build; and a U.S. nationwide network of health sciences libraries actively engaged in facilitating access to biomedical information for health professionals and researchers in academic institutions and hospitals [1-2]. Lindberg fully appreciated these assets. In combination with his expectations about advances in computing and communications and in biomedical science, they were the reasons he came to NLM.

Lindberg saw a golden opportunity for NLM to make a positive difference. "What seems needed now is to adapt these general and useful technologies to the specific jobs of biomedicine. Progress might eventually come in any case, but a concerted effort on the part of the National Library of Medicine could speed this up" [3]. For many "specific jobs of biomedicine" there was "an urgent need for improved access by health care professionals and scientists to the fast-growing scientific literature of newly discovered biomedical concepts, treatments, and preventatives - across wide range of practical and theoretical problems" [3]. Helping to meet this need was NLM's mission.

As Lindberg knew well, expanding access to biomedical and health information is a multidimensional - and multidisciplinary - undertaking with no endpoint. The definitions of easy, reliable, and useful are moving targets, affected by changes in available technologies and services and in user expectations [4]. Progress requires work to expand and engage the universe of active users, to increase and enhance the information and data available, and to facilitate effective connections between the two. Technical connections, e.g., a web capable device and Internet access, are essential, but insufficient. Users must be aware of relevant information and data sources, understand their utility, and have an opportunity to provide feedback on the interfaces to them. Intra-organizational arrangements, inter-organizational relationships, and public policies must promote rather than restrict access to biomedical information and data. Highly trained and motivated 
people are needed to build, maintain, and manage reliable systems that "understand" users and connect them to the right information at the right time and place.

Under Lindberg's leadership, NLM worked with many others to expand access to biomedical information in all these dimensions.

\section{Initial Steps Toward Expanded Access}

Lindberg had six priorities when he came to NLM in 1984, all relevant to expanding access to biomedical information [5].

- Increase public and Congressional awareness of NLM and its services.

- Develop a long range plan based on extensive input from NLM users and stakeholders.

- $\quad$ Provide a user-friendly interface to MEDLINE for health professionals [6].

- Initiate the Unified Medical Language System (UMLS) project [7].

- Increase support for biomedical informatics training and research and development of Integrated Academic Information Management Systems (IAIMS) [8-10].

- Improve relationships between NLM and publishers and the commercial information industry [11].

The NLM Board of Regents initiated action on public awareness and long range planning at their October 1984 meeting, the first held after Lindberg's arrival [12]. He and the Board considered both critical to garnering the resources needed for NLM to help health care and biomedical research "... benefit from the dazzling technological discoveries that are available to us now from computer and information science, telecommunications engineering, physics and chemistry" [3]. The positive effects of increased public awareness and advocacy for the compelling recommendations arising from the planning process are described in chapters throughout the book [e.g., 12-14]. An early spectacular result was the establishment of the National Center for Biotechnology Information (NCBI) at NLM in 1988, which had profound effects on expanded access in all its dimensions [12]. As just one example, NCBI's positioning within NLM speeded the creation of robust links between published biomedical literature and multiple levels of biological, chemical, and clinical research data.

Lindberg also moved quickly on the more specific priorities on his initial list [6-11]. Congress added additional funds to the NLM budget for two of them, UMLS and IAIMS, before the initial NLM Long Range Plan was issued in 1987.

Characteristically, Lindberg did not allow attention to major initiatives to get in the way of his desire to know more about NLM's operations and services and to identify opportunities for immediate improvements in access. A good day for Don Lindberg was a day he learned something new. He was pleased and not surprised to find much to admire, e.g., NLM's new online cataloging and indexing systems, and happy when no intervention from him was necessary. He was interested in learning about positive endeavors he could help to advance, as well as any matters ripe for review and change [e.g., 15, 11].

Shortly after his arrival, in response to a request from a key member of NLM's nationwide library network, Lindberg engineered a quick substantive improvement in access. Allison Bunting M.L.S, then Director of the Regional Medical Library at UCLA, "...asked him if it would be possible to change NLM's practice of the nightly 
maintenance shutdown of the NLM computers...it was right in the middle of Hawaii's workday and the librarians in HI were having to come in at 3 am to get their searching done. He readily agreed saying that the least he could do was provide equal access to our 50th state ..." comparable to what was available to online users in Europe [16]. Based on his experience with IBM systems, Lindberg knew there was a way to keep the online system up during a period of low use while accomplishing the system maintenance in parallel. He gave the NLM Office of Computer and Communications Systems the assignment to gradually reduce the downtime. Less than a year after his arrival, NLM's online system was available 24 X 7 [17].

It was the definition of folly to answer Lindberg's technical questions with vague generalities about what could or could not be done. He was, however, an ideal leader for an organization with a large computing and communications operation during a period of immense technical change and explosive growth in use. Lindberg knew access to NLM's resources had to be fast and uninterrupted in the face of constantly escalating use and growing computer security threats. His concurrent appointment as first Director of the National Coordinating Office for High Performance Computing and Communications (HPCC) gave him even greater incentive and opportunity to apply the latest technological developments and security measures to NLM's systems and services [18].

Lindberg arranged for an initial "white hat" penetration test of NLM's production and research computing systems in 1995 before this became common. He readily approved investments necessary to keep NLM at the forefront of high speed communications; to implement the use of biometrics to authorize entry to the computer center (2002); to establish a second offsite hot back-up computing center to insure uninterrupted access to NLM, U.S. National Institutes of Health (NIH), and U.S. Department of Health and Human Services (HHS) systems (2006); to reduce energy consumption in the computer centers; and to be an early tester and adopter of version 6 of the Internet protocol (IPv6) (beginning in 2011). Under the direction of Simon Liu Ph.D. (2000-2010) and Ivor D'Souza M.S. (2010-present), NLM has been a leader in these areas within the Federal government with major positive effects on fast and reliable access to information and data.

Cost is a barrier to access. To put it mildly, Lindberg disliked the necessity of charging users to recover their fair share of the value-added telecommunications costs needed to access NLM's online services. Given the history of this requirement, with intense scrutiny by the Executive Branch and the Congress, and the large real bill for the commercial networks, there was no quick way to change it [19]. However, Lindberg was able to prevent the expansion of charging for access to some new services. Within months of his arrival, he decided not to charge network libraries for using the new DOCLINE automated document request and routing system. This decision hastened broad adoption of a system that decreased effort across the library network, including at NLM, and increased the speed of document delivery to health professionals and scientists.

\section{Direct Access to MEDLINE by Health Professionals}

Lindberg arrived at NLM with a strong desire to make the Library's services more directly useful in health care. Although his interest encompassed NLM's toxicological and chemical databases, his immediate goal was to provide an inexpensive mechanism for direct MEDLINE searching by health professionals using the personal computers 
increasingly available in their offices and homes. This was a logical first step because the content of MEDLINE was useful to health professionals in its current format.

Dorsch, Faughnan, and Humphreys describe the rapid development and deployment of Grateful Med, an inexpensive PC interface to NLM's ELHILL retrieval system with a memorable name [6]. Its release in February 1986, just 15 months after Lindberg initiated its development, was a major early event in the yearlong celebration of NLM's $150^{\text {th }}$ anniversary. Grateful Med was the subject of an active publicity and marketing campaign and intensive outreach to health professionals by librarians in the nationwide library network. Grateful Med was the principal cause of the dramatic increase in individual health professionals, researchers, and students using NLM's online system. From less than a thousand in 1985, the number rose to more than 100,000 by 1996 . Success in expanding access throughout the U.S. encouraged the Congress to increase NLM funding.

Dorsch et al. place Grateful Med in the context of other efforts to increase health professional use of MEDLINE and assess the impact of its short life. Grateful Med's run ended in 1997 when MEDLINE became free to anyone with an Internet connection and a Web browser. Their chapter is the first of several to mention the initial negative response by some librarians, principally in hospitals, to Grateful Med and NLM's unprecedented direct marketing to health professionals and administrators [6,19-21]. Other librarians embraced the role of reaching out and teaching health professionals about Grateful Med. Their experiences informed subsequent expanded outreach efforts by the National Network of Libraries of Medicine [22].

\section{Free MEDLINE Access Worldwide}

As stated previously, Lindberg did not like charging for online access, and he took steps toward providing free service as opportunities arose. In 1991, he approved NCBI's distribution of the MEDLINE citations in which DNA and protein sequences were published along with the sequence data in a CD-ROM product. This evolved into access via the Internet shortly after the arrival of the first Web browser in 1994, setting the stage for NCBI's Entrez system to replace NLM's ELHILL retrieval system a few years later. Also in 1994, an increase in NLM's AIDS funding allowed Lindberg to respond positively to a request from the HIV/AIDS affected community and make the AIDS databases free [23]. This prompted an immediate increase in use.

Making all of MEDLINE free was a more complicated proposition. Current and potential searchers had to obtain Internet connections so the use of commercial telecommunications networks would no longer be necessary. At Lindberg's direction, NLM and the National Network supported initial connections for many hospitals and their libraries. Beyond this prerequisite, NLM's inflexible legacy retrieval system had to be replaced, a World Wide Web interface implemented, and the political issues associated with eliminating charges navigated very carefully.

Kent A. Smith, Lindberg's Deputy Director during the first 20 years of his tenure, provides a quintessential insider's view of the 13-year path leading from Lindberg's arrival at NLM in 1984 to Vice President Gore's first free search of MEDLINE via the Internet in 1997 [19]. Touching on many developments addressed from different perspectives in chapters throughout the book, he explains how the combination of Lindberg's vision and leadership, advances in technology, astute attention to policy 
issues, and help from political supporters and influential advocates led to free access to MEDLINE worldwide in 1997 - and no attempts to undo it.

Many chapters in this book reveal aspects of the tremendous worldwide impact of free access to MEDLINE via PubMed. There were huge increases in the numbers of users and the amount of use. The evidence that a substantial percentage of users were patients and members of the public led to Lindberg's decision to develop new services designed for them, as discussed below. The removal of the cost barrier was key to expanding MEDLINE access to disadvantaged communities and groups in the U.S. and to developing countries [14]. Unfettered access to MEDLINE via PubMed with rich links to full-text and related data had significant positive effects on biomedical informatics research and development [24].

In 1997 few electronic journal articles were freely available on the Web, a fact highlighted by PubMed's links from free MEDLINE citations to articles behind "pay walls" on publishers' websites. Free MEDLINE via PubMed was one of the factors that led Harold Varmus, M.D., then NIH Director, to give NCBI an assignment to build a free archive of full-text biomedical journal articles. This resulted in the release of PubMed Central in February 2000. In turn, the existence of PubMed Central influenced both an increase in the number of free articles available from publishers and the establishment of the mandatory NIH public access policy, effective in 2008 [4]. PubMed Central and the $\mathrm{NIH}$ public access policy encouraged the implementation of similar policies by many other biomedical research funders. The net result has been free worldwide access to millions of articles reporting the results of research related to biomedicine and health.

\section{Health Information for the Public}

During the development of the NLM Long Range Plan, Lindberg the Board of Regents, and some planning panel members seriously considered whether the NLM should expand its services to encompass health information for the public. At that time, they concluded NLM had neither the budget nor an effective delivery mechanism to provide useful services to the public.

In 1997, the public's use of free MEDLINE via PubMed demonstrated the viability of the Internet and Web browsers as a delivery mechanism. Congress also was pursuing the doubling of NIH's budget from 1998 to 2003. In Lindberg's view, an increase of that size required NLM to develop new programs, as well as expand existing ones. Webbased health information services specially designed for the public was a compelling choice.

MedlinePlus, NLM's major information service for patients and the public, was first released with 22 health topics in October 1998. Coincidentally, this was a month after Varmus assigned NLM the responsibility to develop a clinical trials registry, i.e., ClinicalTrials.gov, to meet a legislative requirement for a service enabling patients and their caregivers to find information about trials of drugs for serious conditions $[11,25]$. Responding to these initiatives, the NLM Board of Regents approved a new policy for NLM information services for the public in 1999. The NLM Long Range Plan, 20002005 , identified health information for the public as a high priority.

Backus and Lacroix chronicle the development and evolution of MedlinePlus, now used by hundreds of millions of people annually [26]. They discuss Lindberg's influence on key features, including links to other NLM services, e.g., PubMed, Clinical Trials.gov, and the inclusion of multimedia content. Backus and Lacroix also explain how 
MedlinePlus and other services for the public were shaped by research and user evaluations, with examples of features and services that were added and retired as warranted by changes in technology and the emergence of better alternatives.

Along with MedlinePlus en espanol, which debuted in 2002, MedlinePlus has been a critical component of NLM and library network efforts to expand public access to high quality health information $[14,22]$. Just as many subject specific NLM bibliographic databases, e.g., AIDSLINE, BIOETHICSLINE, were merged into PubMed to reduce duplication and make their unique content available where users gravitate, some specialized NLM services for the public, including a directory of resources in multiple non-English languages and Genetics Home Reference, have been merged into MedlinePlus [27].

The MedlinePlus Connect feature employs the UMLS and standard clinical terminologies and code sets to support links between electronic health records (EHRs) and MedlinePlus information about health conditions, tests, drugs, and procedures. The existence of MedlinePlus Connect influenced the requirement for electronic connections to patient education materials in U.S. regulations for "meaningful use" of EHRs. As a result, many users of patient portals and EHRs have ready access to high quality health information provided by NLM.

\section{Expanded Access to the History of Medicine and Science}

Lindberg had broad interests in the humanities, including a special enthusiasm for history. He quickly identified NLM's history of medicine program as an area where his personal involvement could make a positive difference. Parascandola describes Lindberg's significant contributions to documentation of the history of $20^{\text {th }}$ century developments in science, medicine, and health policy; the digitization of NLM's pre-1963 indexes, historical books, manuscripts, and images; and the expansion of NLM's exhibition program as an outreach mechanism [15].

Lindberg's stature and personal contacts were critical to obtaining important $20^{\text {th }}$ century manuscript materials and participation in conferences and other efforts to document the history of important programs and relatively young scientific fields. Examples include the papers of winners of the Nobel prize in physiology or medicine, the history of the Regional Medical Programs, and the development of the fields of medical informatics and health services research.

The spread of the Internet and the multimedia capabilities of the World Wide Web were particularly valuable for increasing access to the contents of richly illustrated rare books, unpublished manuscript materials and data, and NLM's large collections of historical pictures and films. As described by Parascandola, Lindberg encouraged NLM's Lister Hill Center for National Biomedical Communications to work with the History of Medicine Division to develop innovative ways to expand access to beautiful and fascinating materials in NLM's collection and the historical collections of other institutions.

Lindberg was the prime mover in the expansion of NLM's historical exhibition program, including the addition of the traveling exhibitions which play an important part in outreach to the public. He selected the themes of some major exhibitions and influenced specific topics and artifacts included in many of them. Lindberg was the driving force behind the exhibition entitled Native Voices: Native Peoples' Concepts of Health and Illness. His video interviews with American Indians, Alaska Natives, and 
Native Hawaiians are the core of the exhibition and could not have been obtained without his personal involvement [27-28].

\section{Expanded Access through Partnerships with Publishers and Editors}

NLM is dependent on editors and publishers of biomedical literature for essential source material for its services. Editors and publishers benefit from the increased manuscript submissions, subscriptions (if applicable), and citations that result from the inclusion of works they publish in NLM databases. More use of NLM databases increases these benefits.

Nonetheless, there have been sources of friction between the Library and editors, publishers, and the information services industry, e.g., the release of PubMed Central in 2000. In the years just prior to Lindberg's arrival as NLM Director in 1984, the relationships were particularly strained due to differences about copyright and interlibrary loan, as well as an effort to convince the Congress that MEDLINE was unfair competition for the private sector. Lindberg came to NLM intending to defuse this situation and soon identified opportunities for collaborative efforts, including a campaign to increase the number of biomedical journals published on acid-free "permanent" paper. $[6,11]$.

In a wide-ranging chapter, White, Roderer, and Kotzin describe relationships between Lindberg and publishers and editors during his 30-year tenure and highlight accomplishments that resulted from their collaborations [11]. At bottom, there was a good basis for cooperation. Publishers and editors thought NLM should index more journals, and Lindberg agreed with them. The Library could not immediately expand MEDLINE coverage greatly due to costs and size limitations, but Lindberg intended to move in that direction.

As reported by White et al., under Lindberg's leadership, a range of cooperative projects addressed: expansion in MEDLINE coverage enabled by the transition to publisher-supplied electronic citations and abstracts; editors' influence on expansion of trial registrations in ClinicalTrials.gov; various improvements in the quality of the biomedical journal literature; and access to information in low-income countries and in the face of emergencies and disasters. All these activities expanded access to biomedical and health information.

\section{Librarians and Expanded Access in a Changing World}

Few professions were affected more profoundly - or rapidly - than health sciences librarianship by their clients' access to personal computers, Internet connections, and free Web versions of key professional information sources. The profound impact of technological changes would have occurred in some fashion anyway, but, as Lindberg intended, NLM did indeed "speed this up" for biomedicine and health [3]. NLM information resources provide a foundation for many services provided by health sciences librarians and information specialists. While Lindberg was NLM's Director, that foundation shifted multiple times, sometimes with destabilizing effects. For hospital librarians, these shifts overlapped with changes in health care affecting hospital viability.

As stated earlier, expanding access to biomedical and health information is a multidimensional - and multidisciplinary - undertaking with no endpoint. Librarians and 
information specialists play critical roles in establishing and maintaining efficient access to the best resources and tools for their institutions in the face of change and are essential partners to NLM in increasing awareness and use of evolving NLM services. Providing these partners with the education and training to make even greater contributions to health care, education, and research in a changing world was a recurring theme in NLM long range planning throughout Lindberg's tenure.

Lindberg had a high regard for "... the ability and flexibility of medical librarians...You're almost tempted to say they can do anything" [30,p.41]. NLM applauded, encouraged, and supported health sciences librarians as they established and embraced new roles and worked with the library network, academic institutions, and professional associations to provide education and career development opportunities to help them do so. Funk and Holst provide complementary descriptions of NLM's encouragement and support for new roles for librarians and for their education and training respectively [20-21].

\subsection{NLM and New and Expanded Roles for Librarians}

Carla Funk was Executive Director of the Medical Library Association (MLA) during most of Lindberg's tenure at NLM. She arrived when many MLA members were angry about the Grateful Med marketing campaign and NLM's use of network librarians as a "field force" to expand direct access to NLM databases by health professionals. Funk discusses the long-term positive effects of NLM's support for librarians' role in outreach and training of health professionals, including the transition to a more outward and usercentered approach to their work.

She summarizes NLM grant support for demonstrations of librarians' roles as "informationists" embedded in health care, public health, and research teams. Informationist support from NLM provided early compelling examples of librarians' contributions to research data management. Highlighting her personal interactions with Lindberg over the years, Funk also discusses NLM-MLA partnerships related to librarians' roles in connecting knowledge to EHRs and in promoting health information literacy [20].

Every expansion in NLM programs and services automatically legitimizes and encourages the involvement of other libraries and librarians in related activities within their own institutions. Funk provides the example of NLM's relatively new and important responsibility as the provider of systems used to comply with the U.S. legislative requirements for public access to research results (which MLA strongly supported). NLM and NIH efforts to increase compliance with now-mandatory deposit of articles resulting from U.S. government-funded research in PubMed Central and submission of clinical trial registrations and summary results to ClinicalTrials.gov have engaged and aided librarians in playing important roles in assisting, promoting, and monitoring compliance with these and related requirements within their institutions [20]. As institutional requirements for standards-based research data creation, management, and sharing increase, so do important roles for librarians.

\subsection{NLM and Education, Training, and Career Development for Librarians}

Ruth Holst, a former hospital librarian, Regional Medical Library associate director, and MLA President, describes the great expansion of librarian education, training, and career development initiatives under Lindberg's leadership and the role of strong partnerships 
with the national network, academic institutions, and MLA in the success and amplification of many of them [21]. Examples include: courses related to new NLM programs and priorities, e.g., bioinformatics, health services research, public health, consumer health, disaster preparedness and response; support for scholarships for minority students in master's programs; challenge grants for development of new educational programs; expansion of NLM's existing post-masters Associate fellowship program; and a competitive NLM-Association for Academic Health Sciences Libraries (AAHSL) Leadership Fellowship program to prepare mid-career librarians for directorships in academic libraries.

Lindberg readily supported all NLM initiatives to assist librarians with life-long learning and was instrumental in some of them. These included a highly impactful competitive one-week residential course in medical informatics with a purposely multidisciplinary student body, including librarians, health professionals, and educators and the MLA disaster information specialist certificate program, with courses developed by the national network and NLM [31-32]. In addition to interacting with students in the medical informatics short course for more than 20 years, Lindberg enjoyed his highly valued sessions with NLM Associate Fellows and NLM/AAHSL Leadership Fellows and Mentors. The interactions with Lindberg in these programs demonstrated to many librarians of his respect for them and their profession.

NLM's strong support for a broad array of education, training, and career development assisted U.S. health sciences librarians - and in the case of online offerings many in other countries - in changing the specific ways they contributed to expanded access to biomedical and health information as the world changed around them.

\section{Conclusion}

By any measure NLM was spectacularly successful in expanding access to biomedical and health information and data under Lindberg's leadership. As demonstrated in the specific examples addressed in this chapter, the many others cited, and some not included in the book, NLM collaborated with many partners to expand access in all its dimensions - more users, more types and volumes of information and data, more effective connections between them, and more people capable of building, maintaining, and enhancing all the necessary connections - technical, conceptual, intra- and interorganizational, and policy.

Lindberg's vision of what access to health information could be, his understanding of what was required to achieve it, and his belief that NLM could drive progress in all dimensions contributed to the Library's success. Progress along any dimension, e.g., increasing the information available, assisted and interacted with progress on other dimensions, e.g., reaching more users, motivating the development of better access systems.

The tremendous 30-year growth in the amount of information available from NLM was due in large part to an impressive increase in the number of organizations and individuals creating and submitting it. Libraries had been engaged in the distributed creation of standard data for shared automated databases since the mid-1960s. During Lindberg's tenure at NLM, it became a widespread practice (with less rigorous standardization) for: biomedical scientists, e.g., sequences to GenBank; medical and scientific publishers, e.g., citations and abstracts to MEDLINE/PubMed and full-text articles to PubMed Central; authors, e.g., papers resulting from funded research to 
PubMed Central; and clinical researchers, e.g., clinical trial registrations and summary results to ClinicalTrials.gov. The drivers included: perceived benefit to the submitter, funder requirements, prerequisites for publication in prestigious journals, legal requirements, and serious consequences for non-compliance with legal requirements.

U.S. government requirements also drove expanded access to some NLM resources, e.g., in cases such as clinical terminology standards in which the Library is the producer or official distributor of the authoritative version of something needed to comply with federal regulations NLM helped to develop.

Lindberg was initially surprised by importance of the public policy dimension in expanding access to biomedical and health information. His position as NLM Director educated him about "...the intimate interplay between policy and science. Some things you just can't do without an explicit public policy, which you cannot get without a democratic process" [30, p.40].

In 2016, Lindberg rightfully gave credit for key policy changes to "the influence of the public in promoting clinical research transparency and free access to governmentfunded research results," but the decisions he made and the systems NLM built under his leadership played an essential part [33]. Making MEDLINE free via the Internet in 1997 raised public expectations, and the existence of ClinicalTrials.gov and PubMed Central, both released by NLM in February 2000, made new policies feasible, if not easy, to implement.

\section{References}

[1] Title 42. U.S.C. $§ 286.2011$. National Library of Medicine. [cited 2021 September 1]. Available from: https:www.nlm.nih.gov/about/nlmlaw html

[2] Bunting A. The nation's health information network: history of the Regional Medical Library Program, 1965-1985. Bull Med Libr Assoc. 1987 Jul;75(3 Suppl): 1-62. PMCID: PMC280609.

[3] National Library of Medicine (U.S.) Board of Regents. Long range plan [Internet] Bethesda, MD: U.S. Department of Health and Human Services, Public Health Service, National Institutes of Health; Jan, 1987, p. 3. [cited 2021 September 30]. Available from: https:/collections.nlm.nih.gov/ext/dw/101646837/PDF/101646837.pdf.

[4] Lindberg DA, Humphreys BL. Rising expectations: access to biomedical information. Yearb Med Inform. 2008: 165-72. PMCID: PMC2441483.

[5] Personal communication from Kent A. Smith. September 12, 2020.

[6] Dorsch JL, Faughnan JG, Humphreys BL. Grateful Med: direct access to MEDLINE for health professionals with personal computers. In: Humphreys BL, Logan RA, Miller RA, Siegel ER, editors. Transforming biomedical informatics and health information access: Don Lindberg and the U.S. National Library of Medicine. Amsterdam: IOS Press; 2021.

[7] Humphreys BL, Tuttle MS. Something new and different: the Unified Medical Language System. In: Humphreys BL, Logan RA, Miller RA, Siegel ER, editors. Transforming biomedical informatics and health information access: Don Lindberg and the U.S. National Library of Medicine. Amsterdam: IOS Press; 2021.

[8] Greenes RA, Florance V, Miller RA. Don Lindberg's influence on future generations: The U.S. national Library of Medicine's biomedical informatics research training programs. In: Humphreys BL, Logan RA, Miller RA, Siegel ER, editors. Transforming biomedical informatics and health information access: Don Lindberg and the U.S. National Library of Medicine. Amsterdam: IOS Press; 2021.

[9] Kuo TT, Ohno-Machado L. NLM's sponsorship of research in biomedical informatics (1985-2016). In: Humphreys BL, Logan RA, Miller RA, Siegel ER, editors. Transforming biomedical informatics and health information access: Don Lindberg and the U.S. National Library of Medicine. Amsterdam: IOS Press; 2021

[10] Lorenzi NM, Stead WW. NLM and the IAIMS initiative: cross-institutional academic/advanced systems contributing to the evolution of networked information and resources. In: Humphreys BL, Logan RA, Miller RA, Siegel ER, editors. Transforming biomedical informatics and health information access: Don Lindberg and the U.S. National Library of Medicine. Amsterdam: IOS Press; 2021. 
[11] White MM, Roderer NK, Kotzin S. Dr. Lindberg and scholarly publishing. In: Humphreys BL, Logan RA, Miller RA, Siegel ER, editors. Transforming biomedical informatics and health information access: Don Lindberg and the U.S. National Library of Medicine. Amsterdam: IOS Press; 2021.

[12] Masys DR, Benson DA. Don Lindberg and the creation of the National Center for Biotechnology Information. In: Humphreys BL, Logan RA, Miller RA, Siegel ER, editors. Transforming biomedical informatics and health information access: Don Lindberg and the U.S. National Library of Medicine. Amsterdam: IOS Press; 2021.

[13] Ackerman MJ. The Visible Human project. In: Humphreys BL, Logan RA, Miller RA, Siegel ER, editors. Transforming biomedical informatics and health information access: Don Lindberg and the U.S. National Library of Medicine. Amsterdam: IOS Press; 2021.

[14] Siegel ER. Don Lindberg's outreach legacy at the National Library of Medicine. In: Humphreys BL, Logan RA, Miller RA, Siegel ER, editors. Transforming biomedical informatics and health information access: Don Lindberg and the U.S. National Library of Medicine. Amsterdam: IOS Press; 2021.

[15] Parascandola J. An active contributor: Dr. Lindberg and NLM's historical programs and services. In: Humphreys BL, Logan RA, Miller RA, Siegel ER, editors. Transforming biomedical informatics and health information access: Don Lindberg and the U.S. National Library of Medicine. Amsterdam: IOS Press; 2021.

[16] Bunting A. Personal communication. September 2, 2019.

[17] Lindberg DAB. At the helm of the world's largest biomedical library: 2005 interviews with Donald A.B. Lindberg. In: Ash J, Sitt D, editors. Bethesda MD; U.S. National Library of Medicine, September 4, 2015; p. 20-21. [cited 2021 September 4]. Available from: https://lhncbc.nlm.nih.gov/assets/files/Medical-Informatics-Pioneers_OralHistory_DONALDLINDBERG_2015-09-04_web1.pdf

[18] Ackerman MJ, Howe SE, Masys DR. Don Lindberg, high performance computing and communications, and telemedicine. In: Humphreys BL, Logan RA, Miller RA, Siegel ER, editors. Transforming biomedical informatics and health information access: Don Lindberg and the U.S. National Library of Medicine. Amsterdam: IOS Press; 2021.

[19] Smith KA. Free MEDLINE access worldwide. In: Humphreys BL, Logan RA, Miller RA, Siegel ER, editors. Transforming biomedical informatics and health information access: Don Lindberg and the U.S. National Library of Medicine. Amsterdam: IOS Press; 2021.

[20] Funk CJ. Promoting new roles for librarians and information specialists. In: Humphreys BL, Logan RA, Miller RA, Siegel ER, editors. Transforming biomedical informatics and health information access: Don Lindberg and the U.S. National Library of Medicine. Amsterdam: IOS Press; 2021.

[21] Holst R. Partnering for education and career development for librarians and information specialists. In: Humphreys BL, Logan RA, Miller RA, Siegel ER, editors. Transforming biomedical informatics and health information access: Don Lindberg and the U.S. National Library of Medicine. Amsterdam: IOS Press; 2021.

[22] Shipman JP, Burroughs CM, Rambo N. NLM's library network: a force for outreach. In: Humphreys BL, Logan RA, Miller RA, Siegel ER, editors. Transforming biomedical informatics and health information access: Don Lindberg and the U.S. National Library of Medicine. Amsterdam: IOS Press; 2021.

[23] Dutcher GA. HIV/AIDS Community Information Outreach Program (ACIOP): a landmark NIH conference and an enduring NLM role in meeting the affected community's need for information access. In: Humphreys BL, Logan RA, Miller RA, Siegel ER, editors. Transforming biomedical informatics and health information access: Don Lindberg and the U.S. National Library of Medicine. Amsterdam: IOS Press; 2021.

[24] Miller RA, Shortliffe EH. Donald A.B. Lindberg and the U.S. National Library of Medicine transformed biomedical and health informatics. In: Humphreys BL, Logan RA, Miller RA, Siegel ER, editors. Transforming biomedical informatics and health information access: Don Lindberg and the U.S. National Library of Medicine. Amsterdam: IOS Press; 2021.

[25] McCray AT. Better access to information about clinical trials. Ann Intern Med. 2000 Oct 17;133(8):60914. DOI: $10.7326 / 0003-4819-133-8-200010170-00013$.

[26] Backus JE, LaCroix EM. Providing health information for patients, families, and the public. In: Humphreys BL, Logan RA, Miller RA, Siegel ER, editors. Transforming biomedical informatics and health information access: Don Lindberg and the U.S. National Library of Medicine. Amsterdam: IOS Press; 2021.

[27] Mitchell JA, Fun J, McCray AT. Design of Genetics Home Reference: a new NLM consumer health resource. J Am Med Inform Assoc. Nov-Dec 2004; 11(6): 439-47. DOI: 10.1197/jamia.M1549.

[28] Wood FB, Altemus AR, Siegel ER. Native Voices Exhibition: stories of health, wellness, and illness from American Indians, Alaska Natives, and Native Hawaiians. In: Humphreys BL, Logan RA, Miller RA, Siegel ER, editors. Transforming biomedical informatics and health information access: Don Lindberg and the U.S. National Library of Medicine. Amsterdam: IOS Press; 2021. 
[29] Gottlieb K, Lindquist C, Mala TA, Mau MKLM. Reflections on Dr. Donald A.B. Lindberg and Native Voices. In: Humphreys BL, Logan RA, Miller RA, Siegel ER, editors. Transforming biomedical informatics and health information access: Don Lindberg and the U.S. National Library of Medicine. Amsterdam: IOS Press; 2021.

[30] Donald A.B. Lindberg, interview by Linda A. Watson [Internet] October 31, 2014 [cited 2021 September 30], transcript, MLA Oral Histories. Medical Library Association, Chicago, IL. Available from: https://www.mlanet.org/blog/lindberg-donald-ab-md .

[31] Cimino JJ. The biomedical informatics short course at Woods Hole/Georgia: training to support institutional change. In: Humphreys BL, Logan RA, Miller RA, Siegel ER, editors. Transforming biomedical informatics and health information access: Don Lindberg and the U.S. National Library of Medicine. Amsterdam: IOS Press; 2021.

[32] Reynolds P. Tamanaha I. Disaster information specialists pilot project: NLM/DIMRC. Med Ref. Serv Q. 2010 Oct;29(4):394-404. DOI: 10.1080/02763869.2010.518929.

[33] Lindberg DA, Humphreys BL. Preface- access to knowledge revisited. Yearb Med Inform. 2016: 11-13. DOI: $10.15265 /$ TYS-2016-s026. 